were likely to have fewer side effects than EHDP. The Leeds experience in the treatment of Paget's disease was reviewed by Dr Gibbs. Calcitonin was significantly more expensive than the only oral diphosphonate currently available. EHDP in a dose of $5 \mathrm{mg} / \mathrm{kg} /$ day appeared to be ineffective but in a dose of $20 \mathrm{mg} / \mathrm{kg} /$ day the drug was effective but also led to reduced mineralisation, causing osteomalacia.
Finally Dr Hordon (Leeds) described the use of isotopic bone scanning to detect 'hot spots' over crush fractures of the spine. Half of such fractures could be confirmed by the presence of hot spots irrespective of how long the fracture had been present.

It is hoped to hold the sixth conference in this series on the first Thursday in May 1985.

\title{
Correspondence
}

\section{Osteosclerosis and new bone formation in young onset and late onset rheumatoid arthritis according to rheumatoid factor seropositivity}

SIR, We have recently carried out a radiological survey of hand damage in young onset rheumatoid arthritis (YORA) and late onset rheumatoid arthritis (LORA). ${ }^{1}$ We have selected patients on the basis of their disease onset before and after 65 years of age. Seventy-two patients (38 YORA, 34 LORA) were analysed according to the persistent seropositivity (or seronegativity) for rheumatoid factor (RF). We have observed, as expected, that RF positive patients had significantly greater $x$-ray damage in the carpal-wrist, metacarpophalangeal, and proximal interphalangeal joints than RF negative ones in the YORA group. The same was not true for LORA patients, who showed the same degree of $x$-ray damage, according to Berens and Lin's modified criteria ${ }^{1}$ either in seropositive or seronegative groups.

Recently Burns and Calin ${ }^{2}$ suggested some radiological features that differentiate seronegative from seropositive rheumatoid arthritis. Following their criteria we reexamined the hand $x$-rays of YORA and LORA patients. The following results were obtained:

\begin{tabular}{lllll}
\hline & & $R F+$ & $R F-$ & \\
\hline Osteosclerosis & LORA & $23 \cdot 5 \%$ & $29 \cdot 4 \%$ & NS \\
& YORA & $28 \cdot 6 \%$ & $58 \cdot 8 \%$ & NS \\
Classical & LORA & $47 \cdot 1 \%$ & $41 \cdot 2 \%$ & NS \\
erosions & YORA & $42 \cdot 8 \%$ & $5 \cdot 8 \%$ & p $<0 \cdot 05$ \\
Global symmetry & LORA & $94 \cdot 1 \%$ & $94 \cdot 1 \%$ & NS \\
& YORA & $100 \%$ & $100 \%$ & NS \\
New bone & LORA & $58 \cdot 8 \%$ & $76 \cdot 5 \%$ & NS \\
formation & YORA & $42 \cdot 8 \%$ & $70 \cdot 6 \%$ & NS \\
Fusion & LORA & $17 \cdot 6 \%$ & $11 \cdot 6 \%$ & NS \\
& YORA & $14 \cdot 3 \%$ & $5 \cdot 8 \%$ & NS \\
Carpal & LORA & $35 \cdot 3 \%$ & $41 \cdot 2 \%$ & NS \\
predominance & YORA & $57 \cdot 1 \%$ & $52 \cdot 9 \%$ & NS \\
\hline
\end{tabular}

The mean disease duration was similar in seropositive and seronegative LORA $(6 \cdot 2 \pm 0 \cdot 8$ yr vs. $6 \pm 1 \cdot 2 \mathrm{yr})$ while seropositive YORA were older than seronegative ones $(6.5 \pm 0.78$ yr vs. $5 \cdot 3 \pm 0.92 \mathrm{yr}: \mathrm{p}<0.05)$. Among patients with rheumatoid arthritis lasting longer than two years (46 cases) irrespective of the age onset, osteosclerosis and new bone formation were found in a significantly higher percentage in RF negative patients $\left(\chi^{2} 6 \cdot 33, p<0 \cdot 05\right.$, and $\chi^{2} 5 \cdot 08, \mathrm{p}<0 \cdot 05$, respectively). The other $x$-ray features did not discriminate between groups.

In conclusion we believe that among the radiological features suggested by Burns and Calin only osteosclerosis and new bone formation help to distinguish between seropositive and seronegative rheumatoid arthritis. Several interfering variables like age onset of the disease, disease duration, and of course second line drug treatment should be taken into account when studying rheumatoid patients for $x$-ray changes, damage, and progression.

$\begin{array}{lr}\text { Rheumatic Disease Unit, } & \text { G. F. FERRACCIOLI } \\ \text { University-Hospital, } & \text { F. CAVALIERI } \\ \text { Parma } 43100 & \text { M. MERCADANTI } \\ \text { Italy } & \text { U. AMBANELLI }\end{array}$

\section{References}

1 Ferraccioli G F, Cavalieri F, Mercadanti M, Conti G, Viviano $P$, Ambanelli U. Clinical features, scintiscan characteristics and $x$-ray progression of elderly onset rheumatoid arthritis. Clin Exp Rheumatol in press.

2 Burns $\mathrm{T}$ M, Calin $\mathrm{A}$. The hand radiograph as a diagnostic discriminant between seropositive and seronegative rheumatoid arthritis: a controlled study. Ann Rheum Dis 1983; 42: 605-12.

SIR, I appreciate the opportunity to comment on the letter of Professor Ferraccioli and colleagues. These authors conclude that they found the degree of osteosclerosis and new bone formation helpful in differentiating seropositive from seronegative 'rheumatoid arthritis'. In addition in patients with disease onset below the age of 65 they described a significantly greater number of classical erosions in individuals who were seropositive for rheumatoid factor compared to those who were seronegative. As they rightly point out, there are numerous variables that can interfere with data of this type. Even if one does control all the factors mentioned, one has then to consider the effect of occupational activity, sex, physiotherapy, and other variables. Inevitably these and other factors will explain differences that result from studies of this type. When we performed a comparable investigation at the 
Royal National Hospital for Rheumatic Diseases we found differences between the seropositive and seronegative patients that to some extent paralleled our original Stanford experience and now the Italian data. ${ }^{1}$

Royal National Hospital for

ANDREI CALIN

Rheumatic Diseases,

Upper Borough Walls,

Bath BA1 1RL.

\section{Reference}

1 Lowthian P, Woolf A, Downes J, Gofton J P, Calin A. 'Seronegative rheumatoid arthritis' a distinct radiological entity: a controlled study versus seropositive disease. Ann Rheum Dis 1984; 43: 117-8.

\section{Vertebral rim lesions in dorsolumbar spine}

SIR, I have read with interest the paper by Hilton and Ball ${ }^{\prime}$ describing vertebral rim lesions in the dorsolumbar spine. It implies, inter alia, that transverse tears ('avulsions') of the annulus have not been mentioned before in the literature. However, such tears in the attachment region of the annulus were described and illustrated many years ago by Schmorl and Junghanns ${ }^{2}$ and more recently by VernonRoberts and Pirie. ${ }^{3}$

Hilton and Ball' state, moreover, that 'The avulsed annulus may be recognised radiographically as a small translucency (clinically sometimes referred to as the vacuum phenomenon).' While I agree that the larger annular tears may sometimes be visualised on post-mortem radiographs of thin slabs of spine (the majority are detected by microscopic examination of stained sections), they are not responsible for the well-known vacuum phenomenon which may be seen on clinical radiographs ${ }^{4}$ and which is associated with cleft formation ${ }^{2}$ initially affecting the nucleus pulposus alone and extending to involve the annulus at a later stage. ${ }^{3}$ Current evidence suggests that nuclear clefts, present in almost every spine after middle age, ${ }^{3}$ are initiated by a primary degenerative process commencing in the nucleus. Clearly they should be distinguished from the less frequent annular clefts (avulsions) formed as a result of traumatic episodes or fatigue failure due to repetitive loading of the annular fibres. The excellent paper by Hilton and Ball ${ }^{1}$ supports these important distinctions and is in accord with a personal view that detailed pathological studies of the spine can provide important clues to the pathogenesis of back pain.

B. VERNON-ROBERTS

Department of Pathology,

The University of Adelaide,

Box 498, GPO,

Adelaide,

South Australia 5001

\section{References}

1 Hilton R C, Ball J. Vertebral rim lesions in the dorsolumbar spine. Ann Rheum Dis 1984; 43: 302-7.
2 Schmorl G. Junghanns $\mathrm{H}$. The human spine in health and disease. 2nd American edition translated and edited by $E F$ Besemann. New York and London: Grune and Stratton, 1971.

3 Vernon-Roberts B. Piric C J. Degenerative changes in the intervertebral discs of the lumbar spine and their sequelac. Rheumatol Rehabil 1977: 16: 13-21.

4 Epstcin B S. The spine. A radiological text and atlas. Philadelphia: Lea and Febiger. 1976.

\section{'Seronegative spondarthritis'}

SIR, Dr Malaviya and his colleagues ${ }^{1}$ suggest the need for a name to include their " "unclassifiable" seronegative spondyloarthropathies'. This semantic confusion would not have arisen had the editor of Medicine (Baltimore) been willing to accept the original title of our paper ${ }^{2}$ on the subject, that is 'Seronegative spondarthritis', and instead of the somewhat cumbersome title under which it was published. One of the cornerstones of this concept was the degree of clinical overlap among the constituent diseases, and we have all seen over the years patients with an apparently unequivocal diagnosis of one of these conditions in whom the diagnosis then shifts as other features supervene, and also numerous examples of forme frustes of these diseases. There have also been semantic arguments about the diagnosis of Reiter's disease, especially if incomplete, and its relation to the reactive arthritides, and also additions to the group, including some cases of juvenile chronic arthritis. Fortunately the original concept of seronegative spondarthritis is sufficiently robust to accommodate all these variations, and I would suggest that Dr Malaviya and his colleagues adhere to the name 'seronegative spondarthritis' to describe his patients in the future.

Department of Rheumatology,

IAN HASLOCK Middlesbrough General Hospital,

Ayresome Green Lane,

Middlesbrough,

Cleveland TS5 $5 \mathrm{AZ}$.

\section{References}

1 Prakesh S, Mehra N K, Bhargava S, Malaviya A N. HLA B27 related 'unclassifiable' seronegative spondyloarthropathies. Ann Rheum Dis 1983; 42: 640-3.

2 Moll J M H, Haslock I, Macrae I F, Wright V. Association between ankylosing spondylitis, psoriatic arthritis, Reiter's disease, the intestinal arthropathies and Behçet's syndrome. Medicine (Baltimore) 1974; 53: 343-64.

\section{Unusual case of dermatomyositis}

SIR, We would like to report an unusual case of dermatomyositis, the dermatological aspects of which have been reported elsewhere.

A 23-year-old female civil servant first presented to this hospital in 1948 with an erythematous eruption in the light-exposed areas, pain and weakness of the muscles of the limbs and Raynaud's phenomenon. A diagnosis of 